\title{
REFRACTIVE ERRORS IN CHILDREN BORN BEFORE 32 WEEKS GESTATION
}

\author{
PHILIPPA M. PENNEFATHER ${ }^{1}$, WIN TIN ${ }^{2}$, NICHOLAS P. STRONG ${ }^{1}$, \\ MICHAEL P. CLARKE ${ }^{1}$, JOHN DUTTON ${ }^{3}$ and DAVID G. COTTRELL ${ }^{4}$ \\ Newcastle upon Tyne and Southport
}

\begin{abstract}
SUMMARY
Purpose: To document the refractive errors in a cohort of children born before 32 weeks gestation.

Methods: All children born before 32 weeks gestation between 1 January 1990 and 31 December 1991 to mothers resident in the Northern Region of the National Health Service were examined at 2 years old $(n=558)$.

Results: Stage 3 or worse retinopathy of prematurity (ROP) was associated with myopia. In those not developing stage 3 or worse ROP, the refractive errors were myopia in $1.5 \%$, hypermetropia $>4$ dioptres (D) in $5.4 \%$, anisometropia $>1 \mathrm{D}$ in $1.1 \%$ and astigmatism $>1.25 \mathrm{D}$ in $\mathbf{5 . 7 \%}$.

Conclusion: The incidence of refractive errors in those not developing stage 3 or worse ROP was similar to that in the general population.

Premature birth is associated with an increased risk of ocular abnormalities, ${ }^{1-8}$ particularly retinopathy of prematurity (ROP). ${ }^{1-10}$ Cicatricial ROP is associated with myopia which is often marked ${ }^{1-3}$ and some studies have shown a higher incidence of myopia in those with extremely low birth weight independent of the effect of ROP. ${ }^{1,2}$ Previous large studies have been biased by selection criteria or a low rate of follow-up to 2 years old. ${ }^{1-7}$ Therefore, this study aimed to document all the refractive errors in a geographically defined population of children born before 32 weeks gestation.
\end{abstract}

\section{METHODS}

The study group consisted of all children born before 32 weeks gestation between 1 January 1990 and 31 December 1991 to mothers resident in the Northern

From: Departments of ${ }^{1}$ Ophthalmology and ${ }^{2}$ Paediatrics, Royal Victoria Infirmary, Newcastle upon Tyne; ${ }^{3}$ Department of Clinical Audit, Southport and Formby District General Hospital, Southport; ${ }^{4}$ Department of Ophthalmology, Newcastle General Hospital, Newcastle upon Tyne, UK.

Correspondence to: Mrs P. M. Pennefather, Department of Ophthalmology, St Paul's Eye Unit, Royal Liverpool University Hospital, Prescot Street, Liverpool L7 8XP, UK.
Region of the National Health Service, who survived until 2 years old $(n=558)$. This region has a population of approximately 3 million. Informed parental consent and ethics committee approval were obtained.

\section{Examination of Children at 2 Years}

All children were reviewed by one ophthalmologist when aged between 2 and 3 years. The examiner was masked to gestational age, neonatal events and all hospital notes. A retrospective review of the hospital notes was made later to determine the clinical signs noted when the child had been screened for acute ROP as a neonate.

Examination comprised visual acuity (usually by Kay pictures), cover tests for near and distant targets, extraocular movements and fields to confrontation. Topical cyclopentolate $1 \%$ was instilled 20 minutes prior to refraction and fundoscopy. Refraction results were corrected for working distance but no additional adjustment was made for the effect of topical cycloplegics. The spherical equivalent was calculated as the mean of the refraction values in the two principal meridians. The refractive errors considered significant were myopia, hypermetropia $>4$ dioptres (D), anisometropia $>1 \mathrm{D}$ and astigmatism $>1.25$ D. Cicatricial ROP was defined as tractional changes of the posterior pole vessels or at the periphery or worse.

\section{Retrospective Review of Patient Records}

Once the child had been examined, all available notes were reviewed for any additional information such as the outcome of ocular examination under anaesthetic or cranial ultrasound scans. This information was used to augment that obtained from clinical examination.

Neonatal records were reviewed for the results of screening for acute ROP and treatment by cryotherapy. Screening for acute ROP had been performed in individual neonatal units by local ophthalmologists. In general, neonates were examined first at 32 weeks

Eye (1997) 11, 736-743 ㅇ 1997 Royal College of Ophthalmologists 
after pupil dilation with phenylephrine $2.5 \%$ and cyclopentolate $0.5 \%$, using indirect ophthalmoscopy with a speculum and an indentor to rotate the eye. Findings were documented in accordance with the international classification of ROP ${ }^{11}$ namely: stage 1 , demarcation line; stage 2, ridge; stage 3 , extraretinal fibrovascular proliferation; stage 4, partial retinal detachment; stage 5, retinal detachment. Threshold disease was defined as in the Multicenter Trial of Cryotherapy for Retinopathy of Prematurity study, ${ }^{7}$ namely at least five contiguous clock-hours or eight cumulative hours of stage 3 ROP in zone 1 or 2 in the presence of 'plus' disease (dilatation and tortuosity of the posterior retinal vessels).

\section{RESULTS}

Of the 565 eligible children, 558 2-year-olds (98.8\% of the study group) were examined. A total of 262 neonates $(47.0 \%)$ were known to have been screened for acute ROP, findings being recorded as no ROP in 400 eyes, stage 1 in 42 eyes, stage 2 in 32 eyes and stage 3 in 32 eyes. Results were not available for 18 eyes. Only one examination for acute ROP was recorded for 94 neonates recorded as no ROP (at a mean post-menstrual age of 35.6 weeks, standard deviation 2.3). Cicatricial ROP developed in 27 eyes, including 8 eyes which had not been screened for acute ROP, 2 eyes recorded as no ROP and 13 eyes which had received cryotherapy. Retinal detachment prevented refraction in 4 of these 27 . Of the 32 eyes with stage 3 ROP, 5 were below threshold and regressed spontaneously, and 13 regressed after cryotherapy leaving a normal posterior pole at 2 years old.

Figure 1 shows the refraction of all eyes with cicatricial ROP or which showed stage 3 acute ROP. Cicatricial ROP was associated with myopia in 20 of $23(87.0 \%)$ eyes (range $-1.125 \mathrm{D}$ to $-21.50 \mathrm{D})$ and significant astigmatism in 7 (30.4\%; range $2-4 \mathrm{D}$; Fig. 1). The only significant refractive error present in children with regressed ROP after cryotherapy was myopia in 3 of 13 eyes $(23.1 \%$; range -0.25 to -5.25 D; Fig. 1). The only significant refractive error present in children with regressed, subthreshold stage 3 ROP was myopia in 1 of 5 eyes $(20 \%$; -1 D; Fig. 1).

Figs. 2-5 show the refraction in the right eye of all children excluding those who developed stage 3 or worse acute ROP, according to worst stage of acute ROP reached. There were no apparent trends in the refraction between children without acute ROP and those developing stage 1 or 2 . Also there were no apparent trends in the refractive errors according to gestational age (excluding those who developed stage 3 or worse acute ROP; Table I).

Increasing severity of ROP was associated with a myopic shift in the spherical equivalent $(p<0.00005$; Fig. 6). The significant differences responsible for this relationship were firstly between those with ROP less than stage 3 and those reaching stage 3 $(p=0.002)$ and secondly between those whose ROP regressed after cryotherapy and those who developed cicatricial ROP $(p<0.0001)$. (The number of eyes reaching sub-threshold stage 3 ROP which

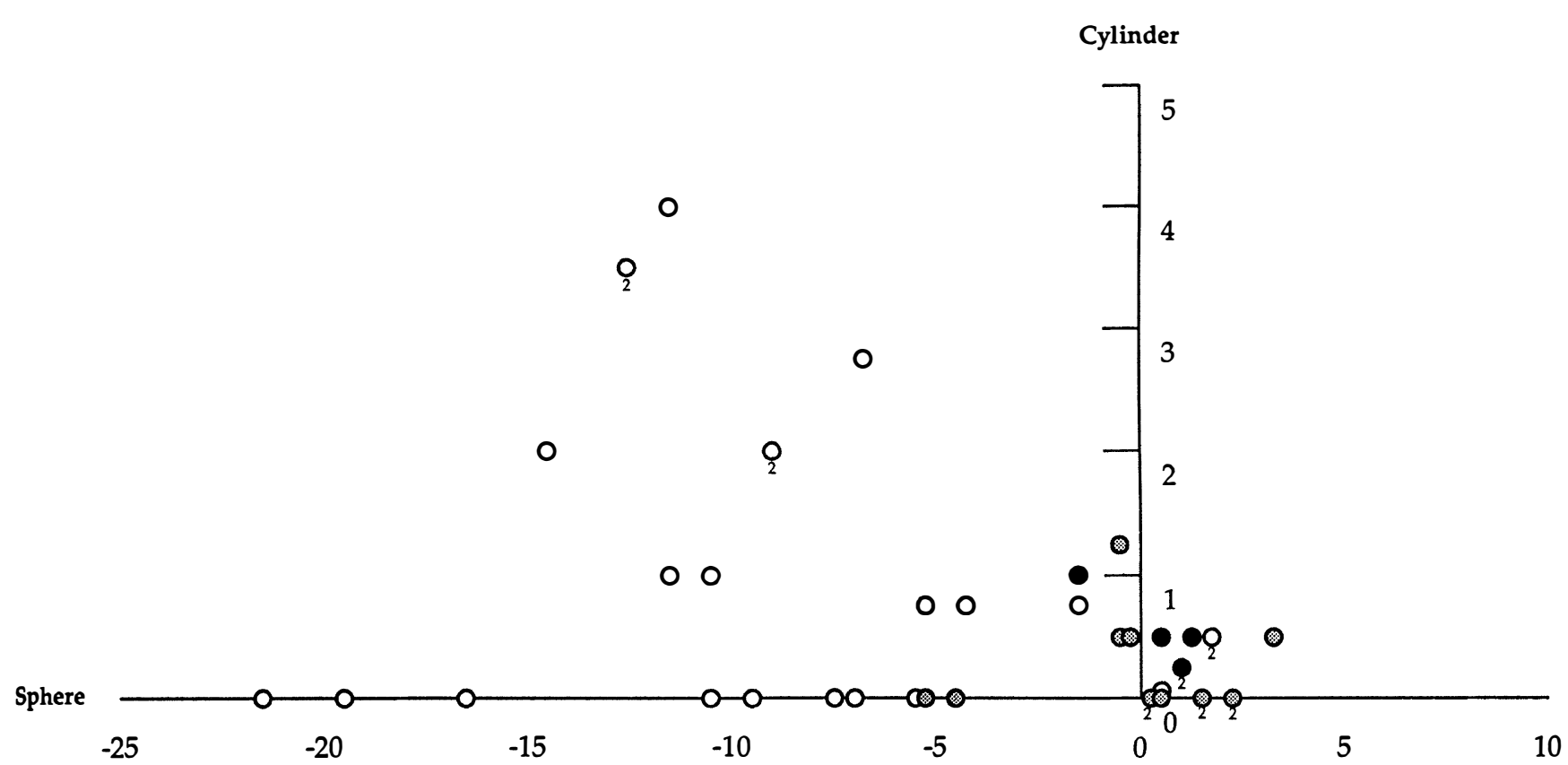

Fig. 1. Refraction (dioptres) at 2 years of eyes which developed stage 3 or worse acute retinopathy of prematurity (ROP) or cicatricial ROP. Filled circles, regressed subthreshold stage 3 acute ROP; grey circles, threshold stage 3 ROP which regressed after cryotherapy; open circles, cicatricial ROP. 


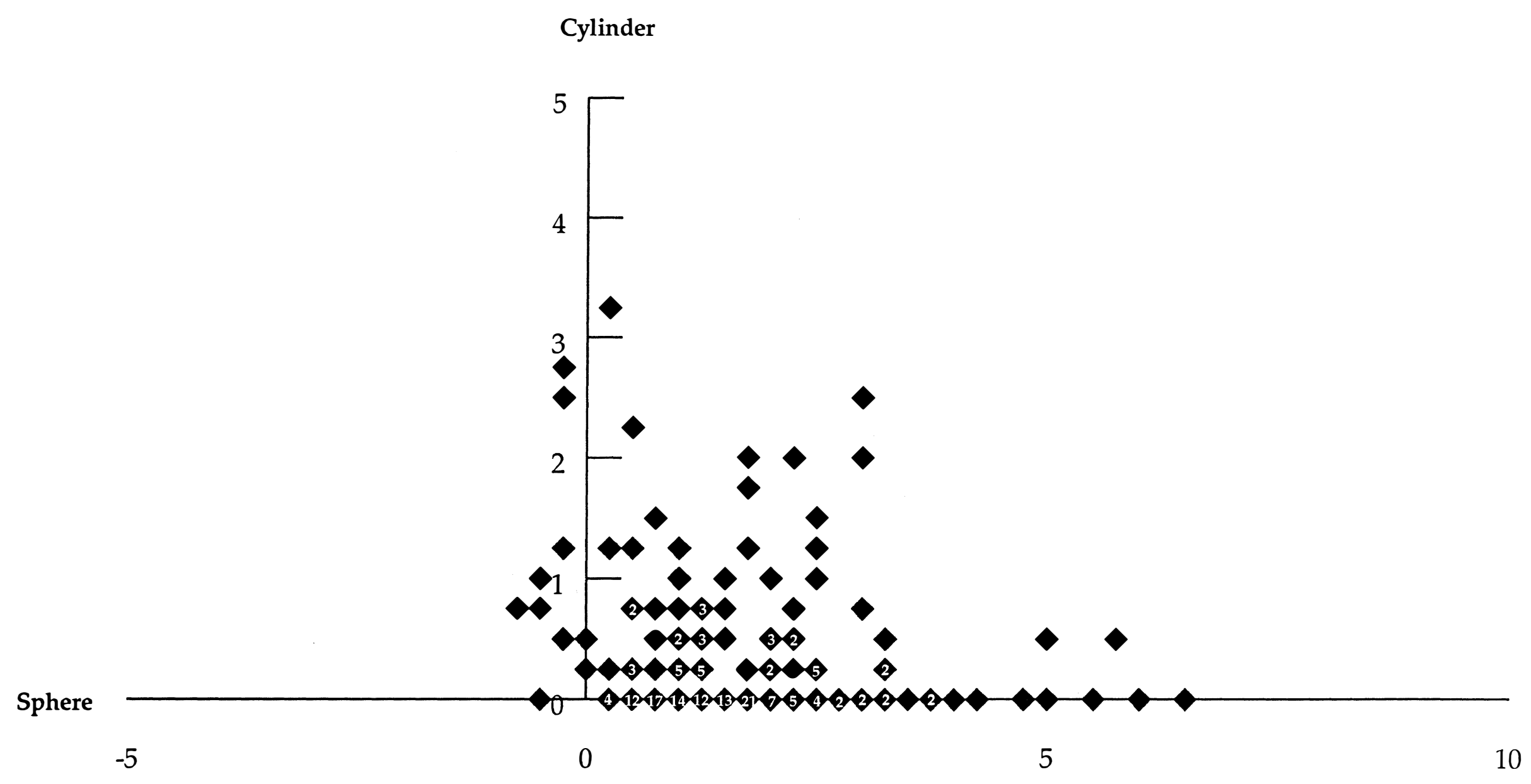

Fig. 2. Refraction (dioptres) at 2 years of right eyes of children born before 32 weeks gestation which did not develop acute ROP. 


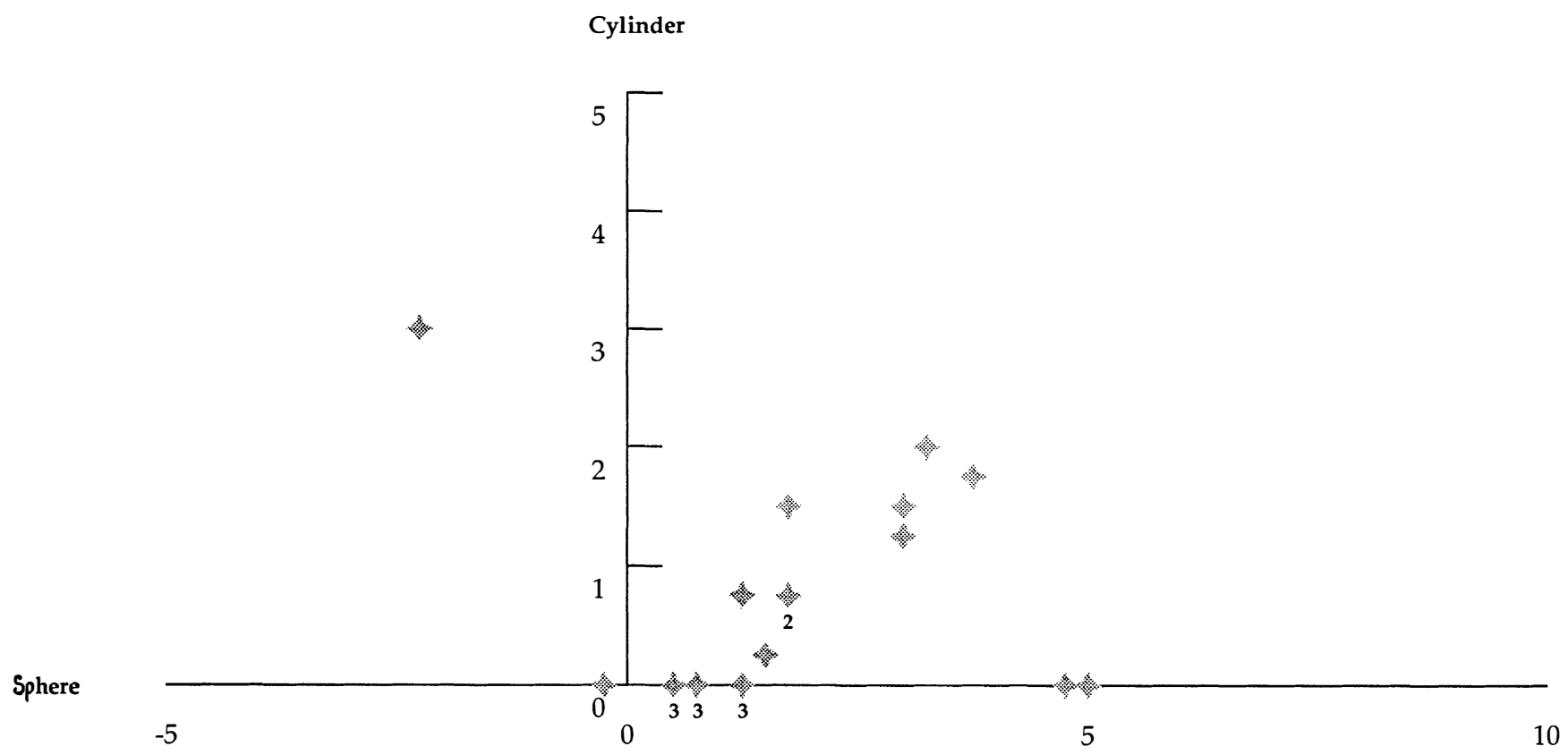

Fig. 3. Refraction (dioptres) at 2 years of right eyes of children born before 32 weeks gestation which developed stage 1 acute $R O P$.

regressed spontaneously was too small for separate analysis.)

\section{DISCUSSION}

This study has documented the refractive errors present in a cohort of children born prematurely. It confirms the association of cicatricial ROP with myopia, astigmatism and anisometropia found in earlier studies. ${ }^{1-3}$ Previous studies have suggested an increase in myopia in those with regressed mild acute $\mathrm{ROP}^{1}$ or in low birth weight children in the absence of acute ROP..$^{1.2}$ In this study the degree of myopia was strongly related to the severity of ROP (as previously described ${ }^{1-3}$ ) but the significant differences in myopia occurred with stage 3 acute ROP or worse. There was no significant difference between those with no ROP and those with stage 1 or 2 . It is possible that some of the neonates documented as having no ROP but seen only once, may have developed undetected mild acute ROP which could reduce any difference in refraction between these groups. However, the absence of a difference

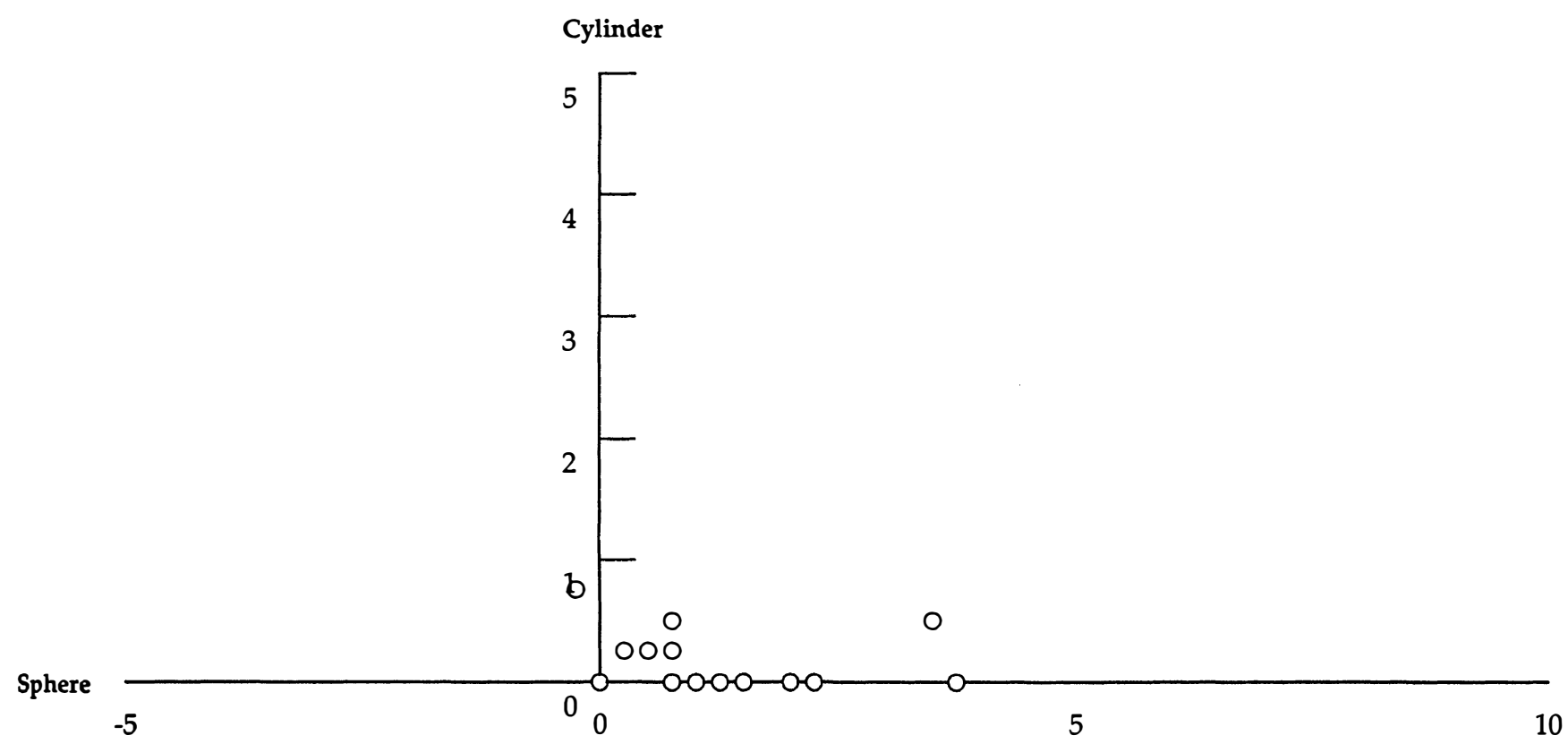

Fig. 4. Refraction (dioptres) at 2 years of right eyes of children born before 32 weeks gestation which developed stage 2 acute $R O P$. 


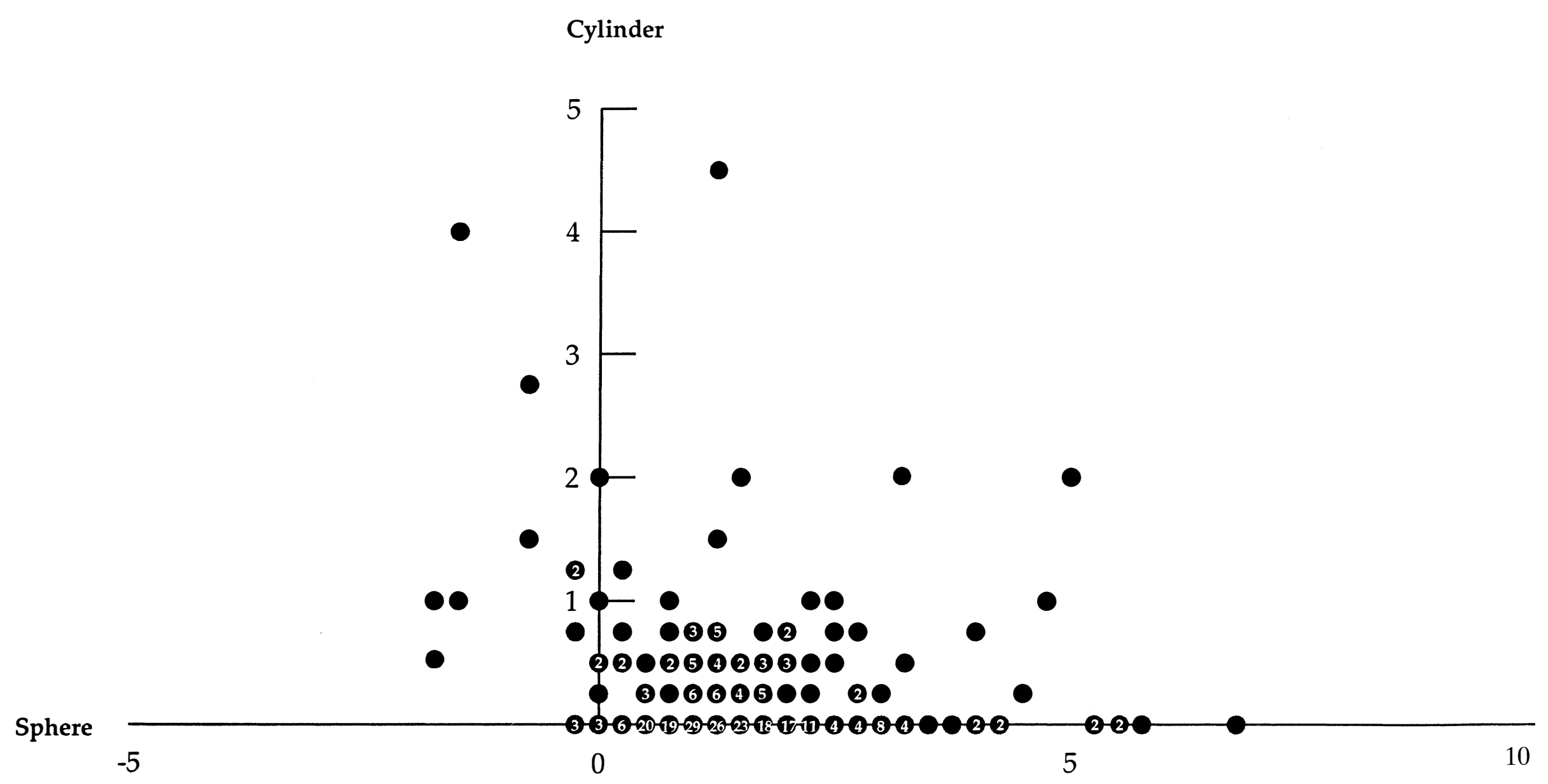

Fig. 5. Refraction (dioptres) at 2 years of right eyes of children born before 32 weeks gestation who were not screened for acute ROP. 


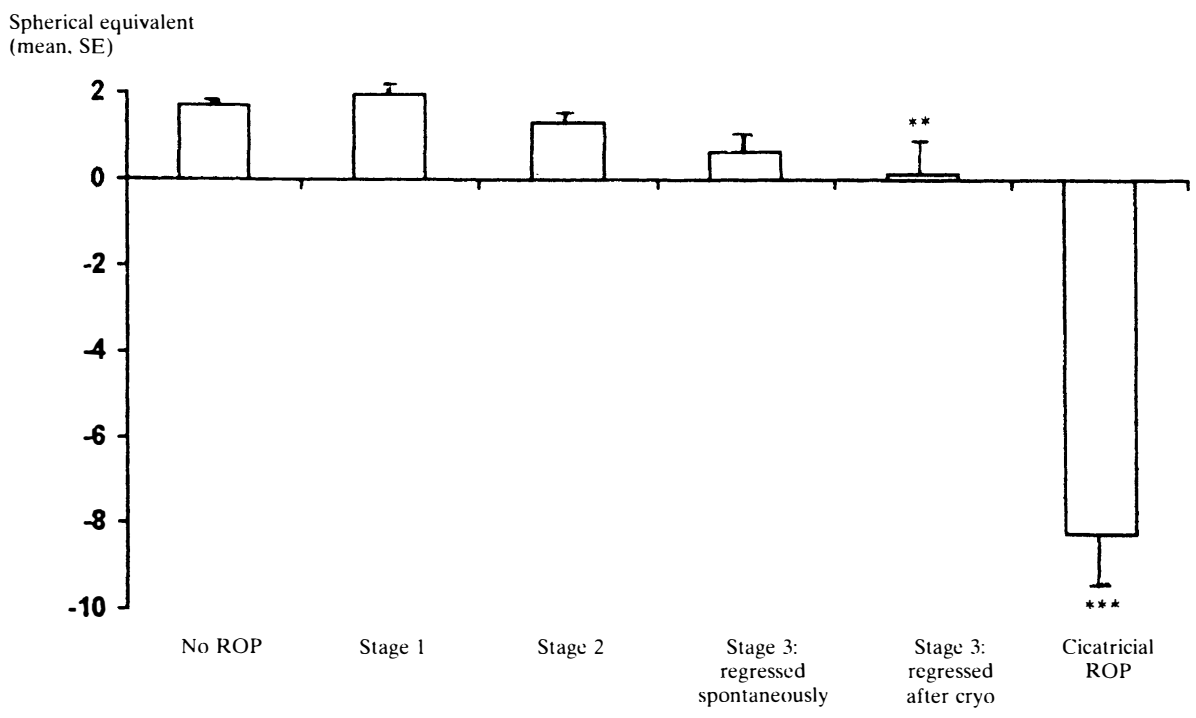

Fig. 6. Mean spherical equivalent according to severity of ROP in eyes of children born before 32 weeks gestation and screened for acute ROP. ${ }^{* *} p=0.009$ compared with those with no ROP or stage 1 or $2 ; * * * p<0.0001$ compared with those with stage 3 ROP which regressed after cryotherapy.

between the groups with no acute ROP, stage 1 or stage 2 is consistent with other studies. Thus the CRYO-ROP study ${ }^{1}$ also showed a strong relationship between the incidence of myopia and the severity of ROP. However, no breakdown was given as to the significance of differences between each stage of ROP. The incidence of myopia in the groups with no ROP and stage 1 and 2 showed a trend for increased myopia with increased severity of ROP, but the incidence in these three groups was similar and considerably lower than in children with stage 3. Similarly Robinson and $\mathrm{O}^{\prime} \mathrm{Keefe}^{4}$ found a trend for increased myopia with increased severity of ROP, with the significant difference occurring with stage 3 ROP.

The incidence of myopia in those without cicatricial ROP is lower in this study $(2.0 \%)$ than others $(4-19.2 \%){ }^{1-6.9}$ This may be partly related to the selection criteria. This study was drawn from a geographically defined population and was based solely upon gestational age (which is more closely related to $\mathrm{ROP}^{10}$ ), rather than upon birth weight ${ }^{1,2,6,9.12}$ or a combination of birth weight and gestational age. ${ }^{3.4 .7}$ Differences in selection criteria are unlikely to be solely responsible for all the differences in myopia in those without cicatricial ROP, as myopia was not independently related to gestational age in this or other studies. ${ }^{1.12}$ The CRYO-ROP study ${ }^{1}$ found a relationship between myopia and birth weight (but not gestational age), but the effect was small compared with the 'overwhelming influence' of the severity of ROP, and Shapiro et al. ${ }^{12}$ found no relationship between birth weight and refractive error. Some differences may be due to the use of data from only those children still under routine review at 2 years. 2.4

Some of the discrepancy between this and previous studies could be explained by the possible use in the other studies of a correction factor for the effect of cycloplegia. The degree of myopia in previous

Table I. Refractive errors in one or both eyes of children born before 32 weeks gestation, excluding those who developed stage 3 or worse acute retinopathy of prematurity

\begin{tabular}{|c|c|c|c|c|c|c|}
\hline $\begin{array}{l}\text { Gestational } \\
\text { age (weeks) }\end{array}$ & $\begin{array}{l}\text { Total no. } \\
\text { of children }\end{array}$ & $\begin{array}{l}\text { Total with } \\
\text { refractive error }(\%)\end{array}$ & $\begin{array}{l}\text { Anisometropia } \\
(>1 \text { D })\end{array}$ & $\begin{array}{l}\text { Astigmatism } \\
(>1.25 \mathrm{D})\end{array}$ & $\begin{array}{l}\text { Hypermetropia } \\
(>4 \mathrm{D})\end{array}$ & $\begin{array}{c}\text { Myopia } \\
(>-0.25 \mathrm{D})\end{array}$ \\
\hline$<24$ & 2 & & & & & \\
\hline $24-24.9$ & 5 & $1(20.0)$ & & & & 1 \\
\hline $25-25.9$ & 15 & $2(13.3)$ & & 1 & 1 & \\
\hline $26-26.9$ & 25 & $8(32.0)$ & & 3 & 5 & 1 \\
\hline $27-27.9$ & 49 & $6(12.2)$ & 2 & 2 & 2 & 2 \\
\hline $28-28.9$ & 66 & $5(7.6)$ & & 4 & 1 & \\
\hline $29-29.9$ & 95 & $8(8.4)$ & 1 & 4 & 3 & 1 \\
\hline $30-30.9$ & 139 & 19 (13.7) & 1 & 12 & 6 & 1 \\
\hline $31-31.9$ & 146 & 17 (11.6) & 2 & 5 & 11 & 2 \\
\hline Total (\%) & $542(100)$ & $66(12.2)$ & $6(1.1)$ & $31(5.7)$ & $29(5.4)$ & $8(1.5)$ \\
\hline
\end{tabular}


studies was generally low so the use of a correction factor could have a significant effect. It seems unlikely that our omission of a correction factor led to an underestimate of true myopia as uncorrected visual acuity was good $(71.4 \%$ of emmetropic children achieved $6 / 6$ or better). Unfortunately the lack of a control group in this and most other studies (excluding Kushner ${ }^{8}$ and Fledelius ${ }^{13}$ ) means the difference in the incidence of myopia in those not developing stage 3 acute ROP between different studies is difficult to interpret. Kushner ${ }^{8}$ found no significant difference in the spherical equivalent at 2 years old between low birth weight neonates $(<1500 \mathrm{~g}$, gestational age 25-33 weeks) and term controls. Fledelius ${ }^{13}$ found low birth weight children to be significantly more myopic than controls at approximately 10 years old $(p<0.05)$. However, the distribution of refraction in low birth weight children was 'close to the distribution among the mature children' except for a 'myopic tail' consisting of 8 eyes of 7 low birth weight children with myopia greater than -6 compared with 1 mature child with high myopia. These children were not screened for acute ROP but 3 eyes (including the bilateral case) had cicatricial ROP. The remaining 5 low birth weight children had unilateral high myopia (mean anisometropia $=10.5 \mathrm{D}$, range $3.75-18.5 \mathrm{D}$ ), suggesting that the myopia in these cases may be secondary to acute ROP (possibly after stage 3 acute ROP) and not to prematurity per se.

In the present study, those premature children who did not develop stage 3 acute ROP had a lower incidence of myopia than estimates for the general population of 2-year-olds ${ }^{14,15}$ (suggesting the use of a correction factor) and the incidence of other refractive errors was similar to the general population of 2-year-olds. ${ }^{14,15}$ This suggests that children born prematurely but who do not develop stage 3 acute ROP are not at increased risk of refractive errors when screened at 2-3 years old. Although the majority of ocular growth has occurred before 3 years of age $^{16}$ it is possible that an increased incidence of myopia may develop in older children born prematurely who developed only mild or no acute ROP. Thus McGinnity and Briars ${ }^{6}$ found that low birth weight children reviewed at 7-11 years old had a mean spherical equivalent of $1.24 \mathrm{D}$ compared with $1.67 \mathrm{D}$ in normal birth weight controls $(p<0.05)$, although the proportion with myopia was not statistically significantly different. In Fledelius' study ${ }^{13}$ of low birth weight children at approximately 10 years old (discussed above) the 'myopic tail' which accounted for the difference in refraction between low birth weight children and mature controls was myopia of preschool onset and non-progressive. Therefore it seems unlikely that as the children in this study grow older there will be a major shift in the refraction of those who did not develop stage 3 or worse acute ROP.

In summary, we have documented the incidence of refractive errors in survivors of premature birth. Excluding those who develop stage 3 acute or worse ROP, there was no increased incidence of refractive errors with decreased gestational age. Our results are consistent with previous reports of a strong association between cicatricial ROP and myopia. ${ }^{1-3}$ However, compared with previous studies ${ }^{1-6.9}$ we found a considerably lower incidence of myopia in those who did not develop stage 3 or worse acute ROP.

We are grateful to the neonatal nurses who played a key part in recruiting these children into this prospective region-wide follow-up study, to the parents and children for their cooperation, and to Sister Susan Fritz for the central role she played in maintaining contact with the families after discharge. We appreciate the work of the neonatologists of the Northern Neonatal Forum, particularly Dr Edmund Hey.

Key words: Refractive errors, Prematurity.

\section{REFERENCES}

1. Quinn GE, Dobson V, Repka MX, et al. Development of myopia in infants with birth weights less than 1251 grams. Ophthalmology 1992;99:329-40.

2. Page JM, Schneeweiss S, Whyte HEA, Harvey P. Ocular sequelae in premature infants. Pediatrics 1993;92:787-90.

3. Gallo JE, Holmstrom G, Kugelberg U, Hedquist B, Lennerstrand G. Regressed retinopathy of prematurity and its sequelae in children age 5-10 years. $\mathrm{Br} \mathrm{J}$ Ophthalmol 1991;75:527-31.

4. Robinson R, O'Keefe M. Follow-up study on premature infants with and without retinopathy of prematurity. Br J Ophthalmol 1993;77:91-4.

5. Cats B, Tan KEWP. Prematures with and without regressed retinopathy of prematurity: comparison of long-term (6-10 years) ophthalmological morbidity. J Pediatr Ophthalmol Strabismus 1989;26:271-5.

6. McGinnity FG, Bryars JH. Controlled study of ocular morbidity in school children born prematurely. Br J Ophthalmol 1992;76:520-4.

7. Burgess P, Johnson A. Ocular defects in infants of extremely low birth weight and low gestational age. Br J Ophthalmol 1991;75:84-7.

8. Kushner BJ. Strabismus and amblyopia associated with regressed retinopathy of prematurity. Arch Ophthalmol 1982;100:256-61.

9. Nissenkorn I, Yassur Y, Mashkowski D. Sherf I, BenSira I. Myopia in premature babies with and without retinopathy of prematurity. $\mathrm{Br} \mathrm{J}$ Ophthalmol 1983; 67:170-3.

10. Holmstrom G, el Azazi M, Jacobson L, Lennerstrand G. A population based, prospective study of the development of ROP in prematurely born children in the Stockholm area of Sweden. $\mathrm{Br} \mathrm{J}$ Ophthalmol 1993; 77:417-23.

11. International Committee. An international classification of retinopathy of prematurity. $\mathrm{Br} \mathrm{J}$ Ophthalmol 1984;68:690-7.

12. Shapiro A, Yanko L, Nawratzki I, Merin S. Refractive power of premature children at infancy and early childhood. Am J Ophthalmol 1980;90:234-8. 
13. Fledelius HC. Prematurity and the eye: ophthalmic 10year follow-up of children of low and normal birthweight. Acta Ophthalmol (Copenh) 1976; 128(Suppl): 3-245.

14. Ingram RM, Barr A. Changes in refraction between the ages of 1 and $3 \frac{1}{2}$ years. Br J Ophthalmol 1979; 63:339-42.
15. Fulton AB, Dobson V, Salem D, Mar C, Petersen RA, Hansen RM. Cycloplegic refractions in infants and young children. Am J Ophthalmol 1980;90:239-47.

16. Sorsby A, Benjamin B, Sheridan M. Refraction and its components during the growth of the eye from the age of three. Med Res Council Spec Rep Ser 1961; 301:1-67. 